\title{
Combined Use of Ultrasound-Assisted Liposuction and Limited-Incision Platysmaplasty for Treatment of the Aging Neck
}

\author{
Patrick P. G. M. Rooijens · Hans-Peter Zweep • \\ Werner H. Beekman
}

Received: 9 April 2008/ Accepted: 26 June 2008/Published online: 25 July 2008

(C) The Author(s) 2008

\begin{abstract}
Background Many techniques have been introduced for the surgical treatment of the aging neck. In this study the combination therapy of ultrasound-assisted liposuction and limited-incision platysmaplasty for cervicofacial rejuvenation is presented.

Methods Fifteen female patients (age $=43-75$ years) were treated for grade II-III $(n=2)$, III $(n=6)$, and grade IV $(n=7)$ cervicomental angle deformity. The outcome of surgery was retrospectively evaluated by a panel.

Results Ultrasonic energy was applied for an average of $2 \mathrm{~min}$ (range $=45 \mathrm{~s}-6.5 \mathrm{~min}$ ). The mean aspiration volume was $125 \mathrm{ml}$. No immediate or delayed adjuvant skin reduction was needed in any of the patients. No complications were encountered in this series. After treatment significant improvement of the cervicomental angle was observed.

Conclusion For treatment of all grades of the aging neck we advocate the combination of UAL and limited-incision platysmaplasty. This combination therapy has little morbidity and leads uniformly to significant improvement of the cervicomental angle.
\end{abstract}

Keywords Aging neck - Liposuction · Ultrasonic · Platysmaplasy

\section{P. P. G. M. Rooijens $(\bowtie)$}

Department of Plastic and Reconstructive Surgery, VU Medical

Center, De Boelelaan 1117, 1007 MB Amsterdam,

The Netherlands

e-mail: p.rooijens@vumc.nl

H.-P. Zweep - W. H. Beekman

Department of Plastic and Reconstructive Surgery,

Tergooiziekenhuizen, location Hilversum, Van Riebeeckweg

212, 1213 XZ Hilversum, The Netherlands

\section{Introduction}

Many techniques have been introduced for the surgical treatment of the aging neck [1-13]. Most techniques involve a face-lift procedure. However, this procedure is not necessary for every patient who presents with redundancy of skin or accumulation of fat in the submental area and adjacent neck. They may be satisfied with a less invasive procedure, reducing downtime but still getting an optimal result. Until now, there were no studies in the literature that described the combined use of ultrasoundassisted liposuction (UAL) and limited-incision platysmaplasty for the treatment of the aging neck. In this report the combination therapy of UAL and platysmaplasty for cervicofacial rejuvenation is presented in a retrospective study of 15 selected patients.

\section{Patients and Methods}

Patients

Fifteen patients who sought neck rejuvenation were included in this study. According to the classification advocated by Knize (Fig. 1) [8], two patients were included with a grade II-III, a mild to moderate cervicomental angle deformity; six patients with a grade III, moderate cervicomental angle deformity; and seven patients with a grade IV, severely oblique cervicomental angle (Table 1).

\section{Surgical Technique}

To prevent bias, all patients were treated by one surgeon. The patients were operated on in day-care surgery. All markings were made with the patient in an upright position. 


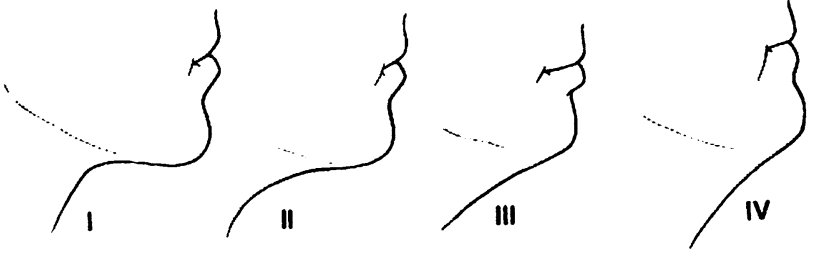

Fig. 1 Classification of cosmetic deformity of the neck. Grade I: normal cervicomental angle; grade II: mild; grade III: moderate; grade IV: severely oblique cervicomental angle [8]

Table 1 Degree of cervicomental angle deformity preoperatively, number of patients treated, and postoperative grade

\begin{tabular}{llll}
\hline $\begin{array}{l}\text { Preoperative } \\
\text { grade }\end{array}$ & $\begin{array}{l}\text { Number of } \\
\text { patients }\end{array}$ & $\begin{array}{l}\text { Postoperative } \\
\text { grade }\end{array}$ & $\begin{array}{l}\text { Number of } \\
\text { patients }\end{array}$ \\
\hline II-III & 2 & I & 1 \\
& & I-II & 1 \\
III & 6 & I-II & 2 \\
& & II & 4 \\
IV & 7 & II & 2 \\
& & II-III & 1 \\
& & III & 4 \\
\hline
\end{tabular}

Concentric topography-type marks were centered on the most prominent portion of the submental region. The incision site just posterior to the submental crease was also defined.

Patients were operated on under general anesthesia in the supine position, with the neck extended on a surgical headrest. Preoperatively $1 \mathrm{~g}$ of flucloxacillin (GlaxoSmithKline BV, Zeist, the Netherlands) was administered intravenously during induction. A stab incision just posterior to the submental crease was made to facilitate tumescent infiltration with a solution of 11 of $0.9 \% \mathrm{NaCl}$, $25 \mathrm{ml}$ of $1 \%$ lidocaine, $1 \mathrm{ml}$ of 1:100,000 epinephrine, and $12.5 \mathrm{ml}$ of $8.4 \%$ sodium bicarbonate [14].

Liposuction was performed using an ultrasonic generator (Lysonix; Mentor Corporation, Santa Barbara, CA) with an open-tip 3-mm cannula. This cannula was passed multiple times in a fanlike pattern to emulsify the fatty tissue. Final evacuation of liquefied fatty tissue and contouring of the neck was performed with a standard 3-mm cannula (Tulip; Tulip Biomed, San Diego, CA).

Subsequently, the platysmaplasty was performed by extending the stab incision up to $3 \mathrm{~cm}$. The submental skin was undermined to the level of the cricoid cartilage and raised with a retractor. The medial platysma muscle edges were identified and raised and the subplatysmal plane was inspected for excess fat depositions. If present, the subplatysmal fat was resected. Finally, the medial platysma muscle edges were approximated in the midline using mattress or figure-of-eight plicating sutures of Vicryl 3-0 (Ethicon GmbH, Johnson \& Johnson, Hamburg, Germany). After secure hemostasis, the wound was closed in layers with interrupted subcutaneous Vicryl 4-0 and a continuous intracutaneous Monocryl 5-0 (Ethicon GmbH, Johnson \& Johnson) suture. A chin strap was worn continuously for 10 days.

\section{Cosmetic Assessment}

Standardized photographs were taken by a professional medical photographer preoperatively and 6 months postoperatively. These photographs were graded by a panel according to the classification of Knize (Fig. 1) [8]. The panel consisted of three plastic surgeons and two plastic surgery residents. Two slides were used for this evaluation: the frontal view of the patient and the left profile.

\section{Results}

The described technique was used for 15 patients (all female) with a mean age of 57 years (range $=43$ 75 years). Ultrasonic energy was applied for an average of 2 min (range $=45 \mathrm{~s}-6.5 \mathrm{~min}$ ). The mean aspiration volume was $125 \mathrm{ml}$ (range $=25-200 \mathrm{ml}$ ). No hematoma, seroma, infection, skin necrosis, contour irregularity, or other complications were encountered in this series. The preoperative status (degree of obliquity of the cervicomental angle) and the postoperative results at 6 months, as graded by the panel, are given in Table 1. After treatment significant improvement of the cervicomental angle was observed (Figs. 2-5).

\section{Discussion}

In our opinion too often a total face-lift procedure is performed to correct the submental laxity. As a result, the deformity is corrected but often visible periauricular scarring may not be avoided. To prevent this, many other techniques have been described. One technique involves cervicoplasty without skin excision, predominantly performed without skin excision $[3,6,7,10]$. Other techniques involve excision of redundant neck skin and fat with platysma plication and Z-plasty closure of the skin $[1,2,9]$, or a platysmaplasty with or without suction-assisted lipectomy of the submental area [5, 8, 11, 12]. Only one article favors a technique of cervicofacial rejuvenation that involves UAL as a single procedure [4].

UAL has several advantages over conventional liposuction. Using UAL, fat is more selectively emulsified, 
Fig. 2 Preoperative (left) grade III and postoperative (right) grade I-II views of patient with cervicomental angle deformity
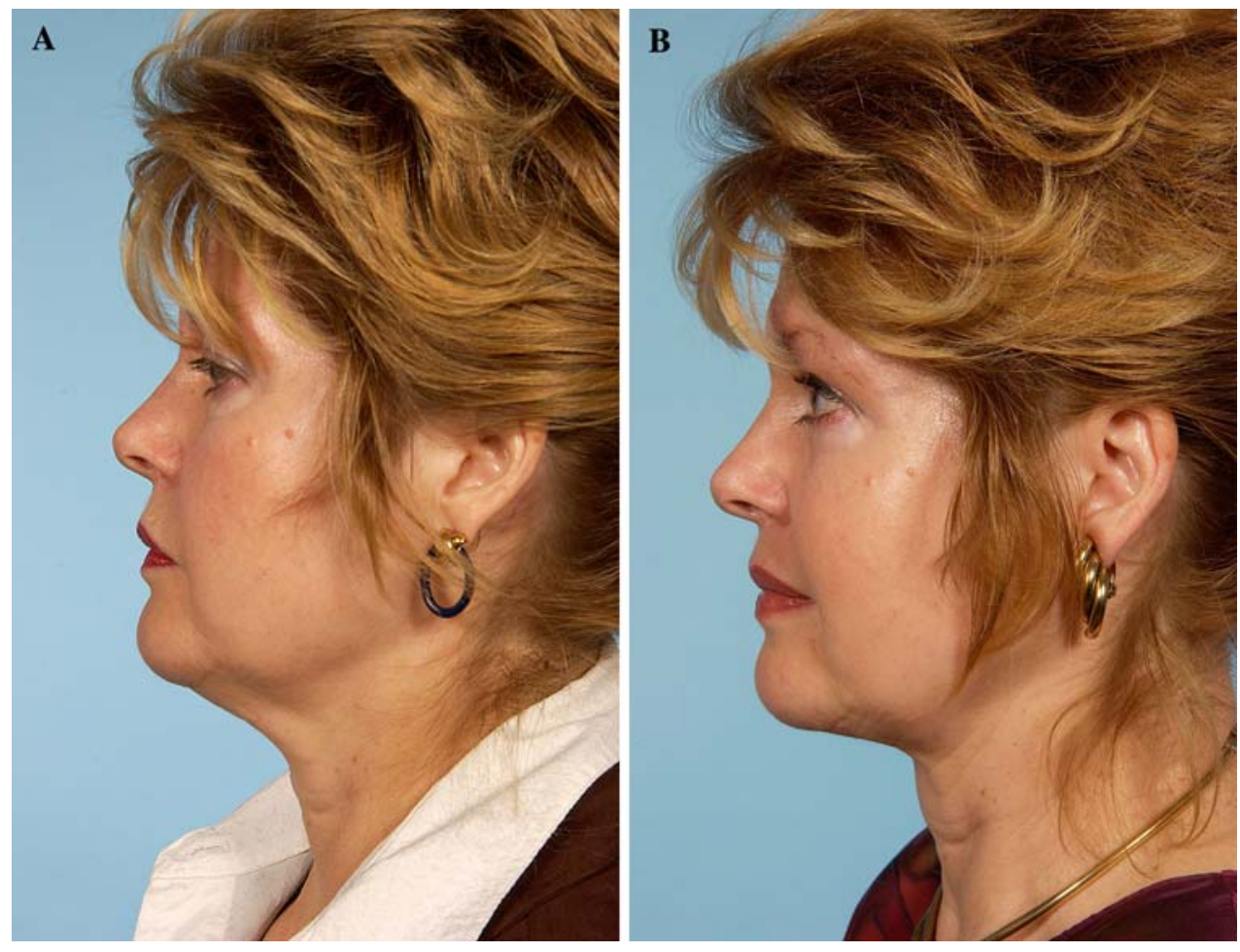

Fig. 3 Preoperative (left) grade III and postoperative (right) grade I-II views of patient with cervicomental angle deformity
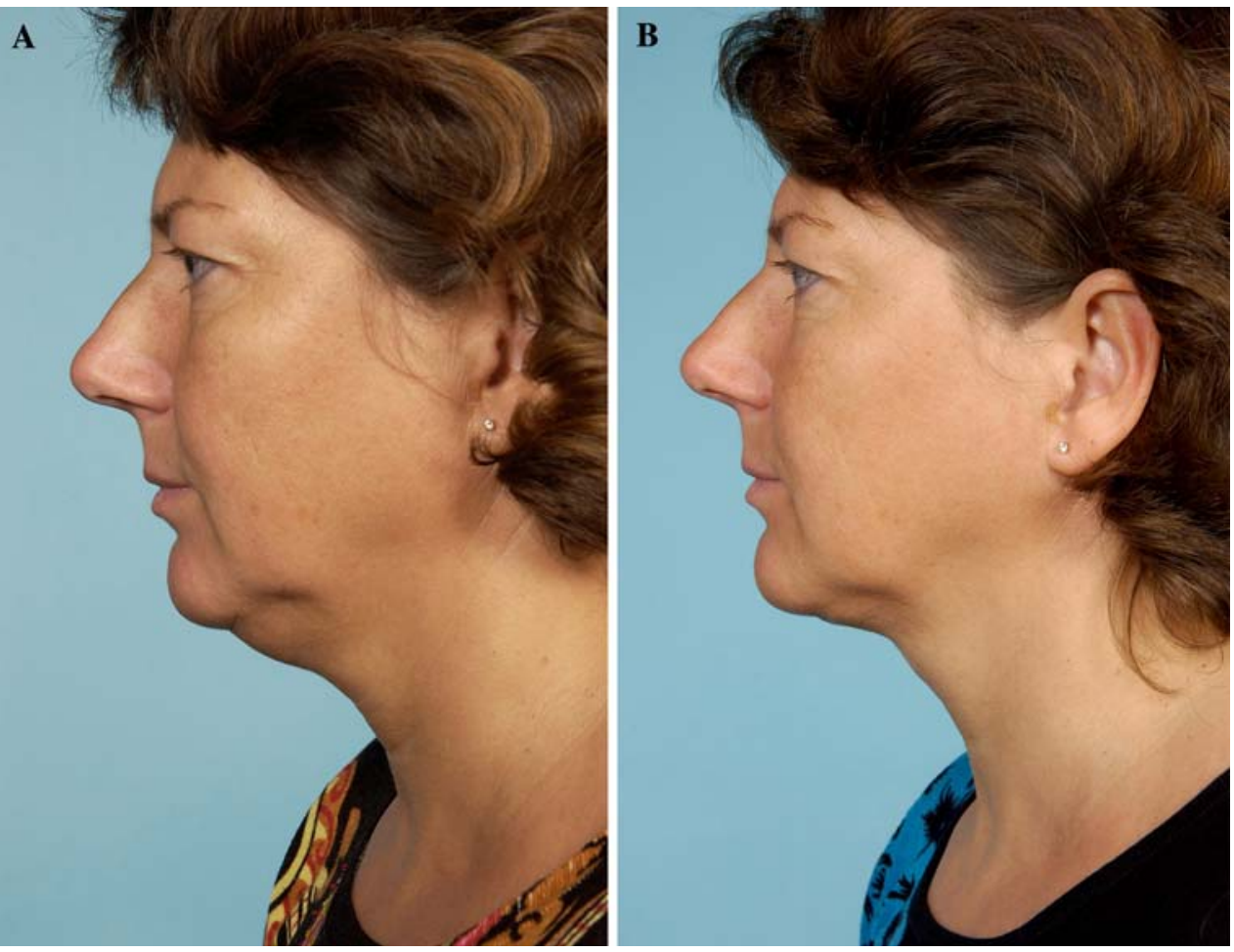

leaving the higher-density fibroconnective tissues relatively undamaged [15-17]. Moreover, UAL performed in the appropriate subdermal plane allows for skin contraction in the postoperative healing period, abolishing the need for adjuvant skin resection [18-20]. Our experience confirmed that UAL could prevent skin excision as a result of considerable skin contraction (Figs. 2-4), even in older patients (Fig. 5). We advocate limiting the application of ultrasound to a few minutes; in this period the rate of emulsification is greater than 
Fig. 4 Preoperative (left) grade II-III and postoperative (right) grade I views of patient with cervicomental angle deformity
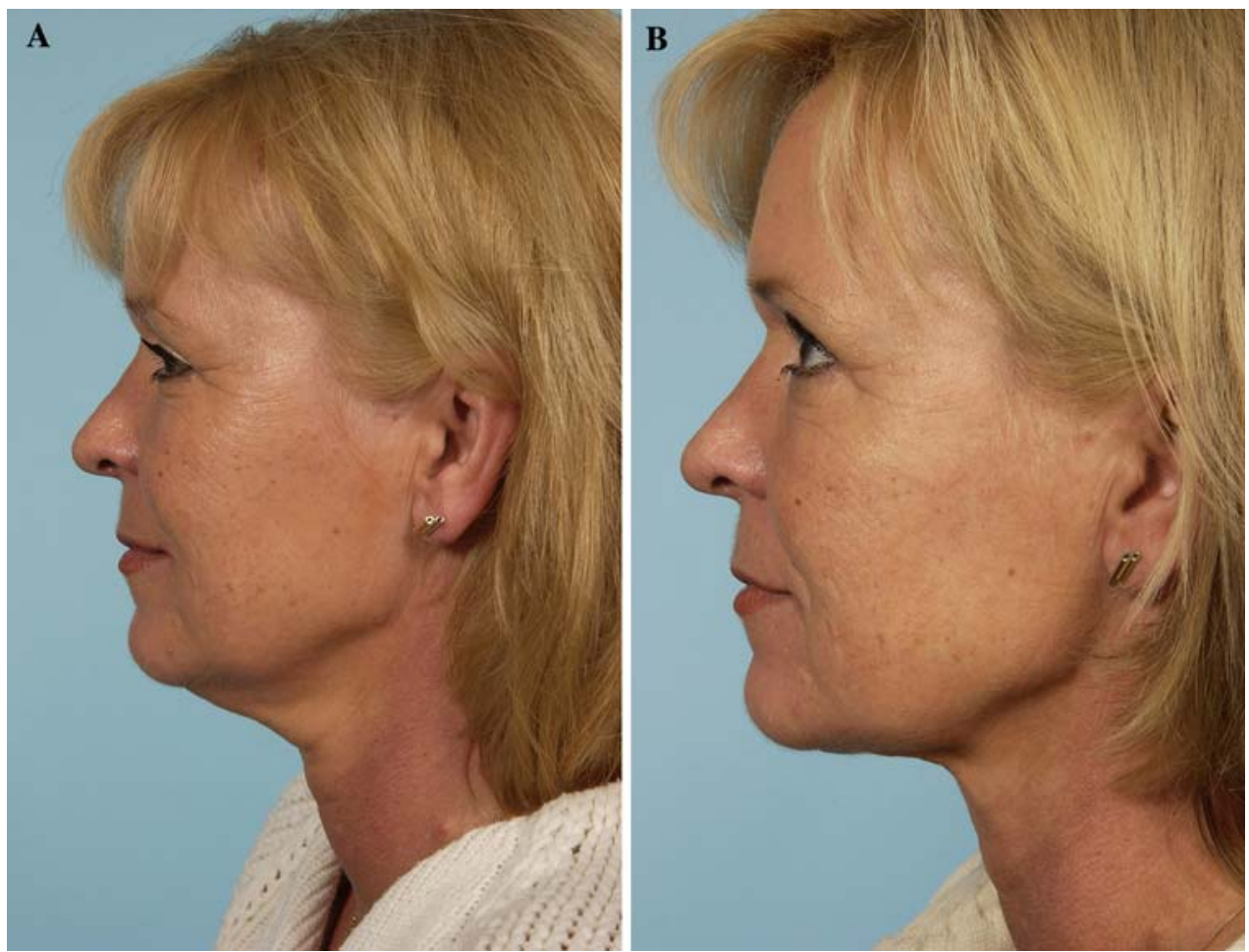

Fig. 5 Skin contraction in a 73year-old patient. Preoperative (left) grade IV and postoperative (right) grade III views of patient with cervicomental angle deformity
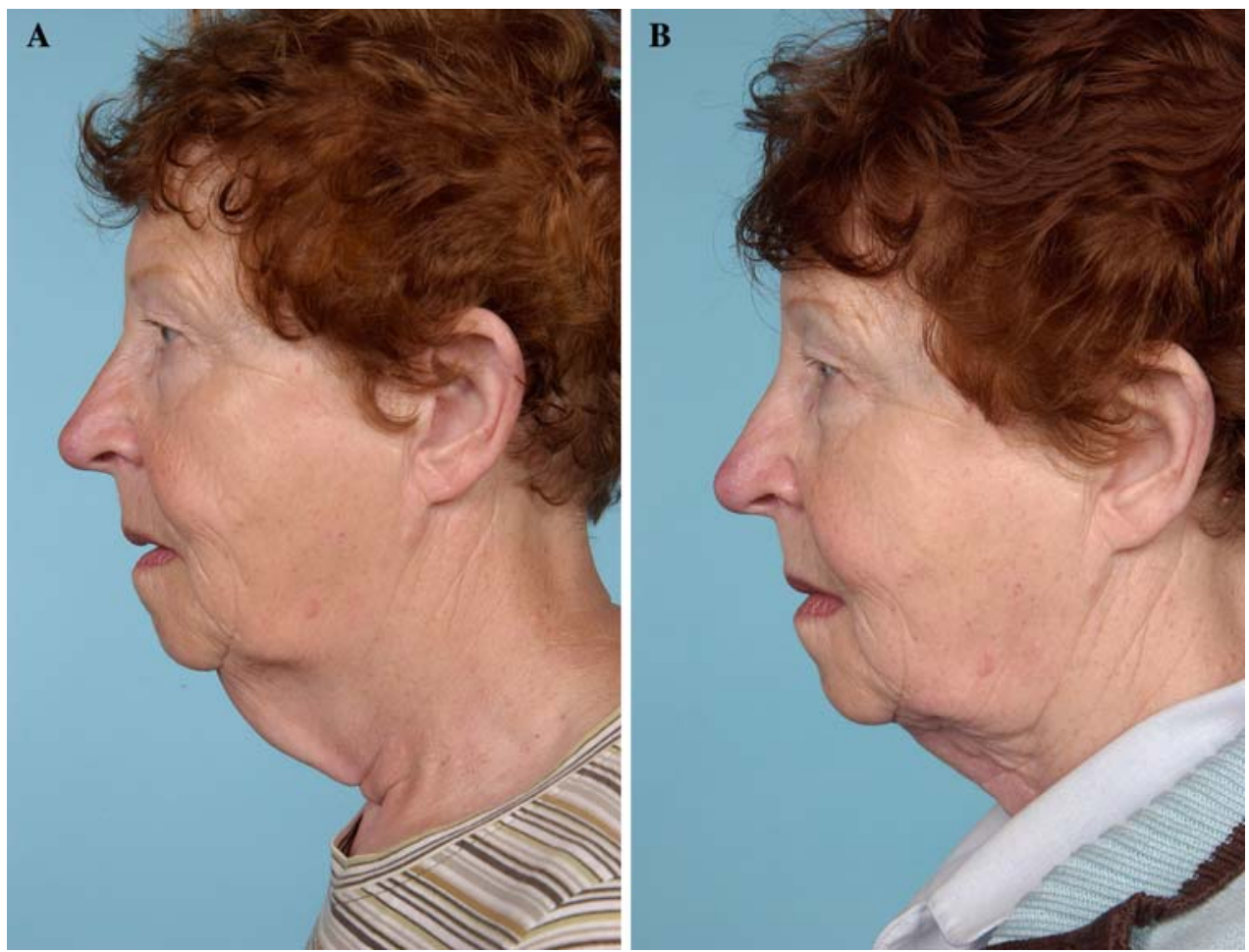

the rate of evacuation. Afterward, we evacuate the residual liquefied tissue by conventional liposuction with a 3-mm cannula. Limiting the period of ultrasound use will help to prevent excessive postoperative seroma formation $[15,21,22]$.
In the present study we observed a significant improvement in the cervicomental angle by using a combination of UAL and limited-incision platysmaplasty. This method produces good, predictable results and is safe. However, patients must be carefully screened and the 
limitations of the procedure clearly spelled out. These patients will obtain improvement in profile only, with no improvement in the midface [13]. Also, many older patients with submental fullness and moderate residual submental skin tone can benefit from this approach (Fig. 5). This procedure also eliminates unnecessary periauricular scarring. This was also concluded by Knize [8], who performed limited-incision submental lipectomy using conventional liposuction and platysmaplasty on 56 patients.

\section{Conclusion}

For treatment of all grades of the aging neck we advocate the combination of UAL and limited-incision platysmaplasty. This combination therapy has little morbidity and leads uniformly to significant improvement of the cervicomental angle.

Open Access This article is distributed under the terms of the Creative Commons Attribution Noncommercial License which permits any noncommercial use, distribution, and reproduction in any medium, provided the original author(s) and source are credited.

\section{References}

1. Biggs TM Jr (1980) T-Z-plasty for the male "turkey gobbler" neck. Plast Reconstr Surg 65:238

2. Cronin TD, Biggs TM (1971) The Z-plasty for the male "turkey gobbler" neck. Plast Reconstr Surg 47:534-538

3. Giampapa VC, Di Bernardo BE (1995) Neck recontouring with suture suspension and liposuction: an alternative for early rhytidectomy candidate. Aesthetic Plast Surg 19:217-223

4. Grotting JC, Beckenstein MS (2001) Cervicofacial rejuvenation using ultrasound-assisted lipectomy. Plast Reconstr Surg 107:847-855

5. Gryskiewicz JM (2003) Submental suction-assisted lipectomy without platysmaplasty: pushing the (skin) envelope to avoid a face lift for unsuitable candidates. Plast Reconst Surg 112:13931405

6. Guerrerosantos J (1978) The role of the platysma muscle in rhytidoplasty. Clin Plast Surg 5:29-49

7. Guerrerosantos J, Ramirez OM, Espaillat L (1972) Ritidoplastia cervicofacial. Rev Lat Am Cir Plast 14:31-33

8. Knize DM (1998) Limited incision submental lipectomy and platysmaplasty. Plast Reconstr Surg 101:473-481

9. Miller TA, Orringer JS (1996) Excision of neck redundancy with single Z-plasty closure. Plast Reconstr Surg 97:219-221

10. Ramirez OM (1997) Cervicoplasty: non-excisional anterior approach. Plast Reconstr Surg 99:1576-1585

11. Singer R (1984) Improvement of the "young" fatty neck. Plast Reconstr Surg 73:582-589

12. Teimourian B (1983) Face and neck suction-assisted lipectomy associated with rhytidectomy. Plast Reconstr Surg 72:627-633

13. Zins JE, Fardo D (2005) The "anterior-only" approach to neck rejuvenation: an alternative to face lift surgery. Plast Reconstr Surg 115:1761-1768

14. Chalekson C, Wilhelmi BJ, Neumeister M (2006) Liposuction, techniques. E-medicine. Available at http://www.emedicine.com/ plastic/topic486. Accessed March 2008

15. Gingrass MK, Kenkel JM (1999) Comparing ultrasound-assisted lipoplasty with suction-assisted lipoplasty. Clin Plast Surg 26:283-288

16. Kenkel JM, Gingrass MK, Rohrich RJ (1999) Ultrasound-assisted lipoplasty. Basic science and clinical research. Clin Plast Surg 26:221-234

17. Kenkel JM, Robinson JB Jr, Beran SJ, Tan J, Howard BK, Zocchi ML, Rohrich RJ (1998) The tissue effects of ultrasound-assisted lipoplasty. Plast Reconstr Surg 102:213-220

18. Grotting JC, Beckenstein MS (1999) The solid-probe technique in ultrasound-assisted lipoplasty. Clin Plast Surg 26:245-254

19. Zocchi ML (1996) Ultrasonic assisted lipoplasty. Technical refinements and clinical evaluations. Clin Plast Chir 23:575-598

20. Zocchi ML (1999) Basic physics for ultrasound-assisted lipoplasty. Clin Plast Chir 26:209-220

21. Maxwell GP, Gingrass MK (1997) Ultrasound assisted body contouring; a clinical study of 250 consecutive patients. Plast Reconstr Surg 101:189-204

22. Rohrich RJ, Berjan SJ, Kenkel JM, Adams WP Jr, DiSpaltro F (1998) Extending the role of liposuction in body contouring with ultrasound-assisted liposuction. Plast Reconstr Surg 101:1090-1102 